\title{
DO PHYSICAL OR PSYCHOSOCIAL FACTORS AT WORK PREDICT MULTI-SITE MUSCULOSKELETAL PAIN? A 4-YEAR PROSPECTIVE STUDY AMONG INDUSTRIAL POPULATION
}

Subas Neupane, ${ }^{1}$ Pekka Virtanen, ${ }^{1}$ Anna Siukola, ${ }^{1}$ Helena Miranda, ${ }^{2}$ Clas-Håkan Nygård ${ }^{1}{ }^{1}$ University of Tampere, Tampere, Finland; ${ }^{2} \mathrm{FIOH}$, Helsinki, Finland

10.1136/oemed-2011-100382.324

Objectives Musculoskeletal pain at multiple sites is common among working-age people and it strongly increases work disability. Little is known of the work-related physical and psychosocial factors contributing to multi-site pain.

Methods Survey responses from 734 employees (518 blue- and 216 white-collar; $65 \%$ female) of a food processing company were collected twice, in 2005 and 2009. Information on musculoskeletal pain during the preceding week, and physical and psychosocial work exposures were obtained through a structural questionnaire. The risk of multi-site pain related to the single and joint effects of work exposures was estimated by gender and age-group with logistic regression.

Results At baseline, $56 \%$ had pain in more than one area, and $50 \%$ at 4 -year follow-up. Forty percent of all employees had multi-site pain throughout the follow-up. Among those with multi-site pain at baseline, $69 \%$ had multi-site pain at follow-up. Both repetitive work and awkward work postures at baseline increased the risk of multi-site pain at follow-up by more than fourfold. Psychosocial factors (low job satisfaction, low team sprit and low possibilities to exert influence at work) also strongly predicted multi-site pain at follow-up, especially among younger workers and men. A strong dose-response relationship was detected between the number of exposures and the outcome.

Conclusions Musculoskeletal pain at multiple sites is a common and persistent phenomenon among industrial workers. Physical and psychosocial factors significantly contribute to multi-site pain. Prevention of multi-site pain with manysided modification of work exposures is likely to reduce work disability. 